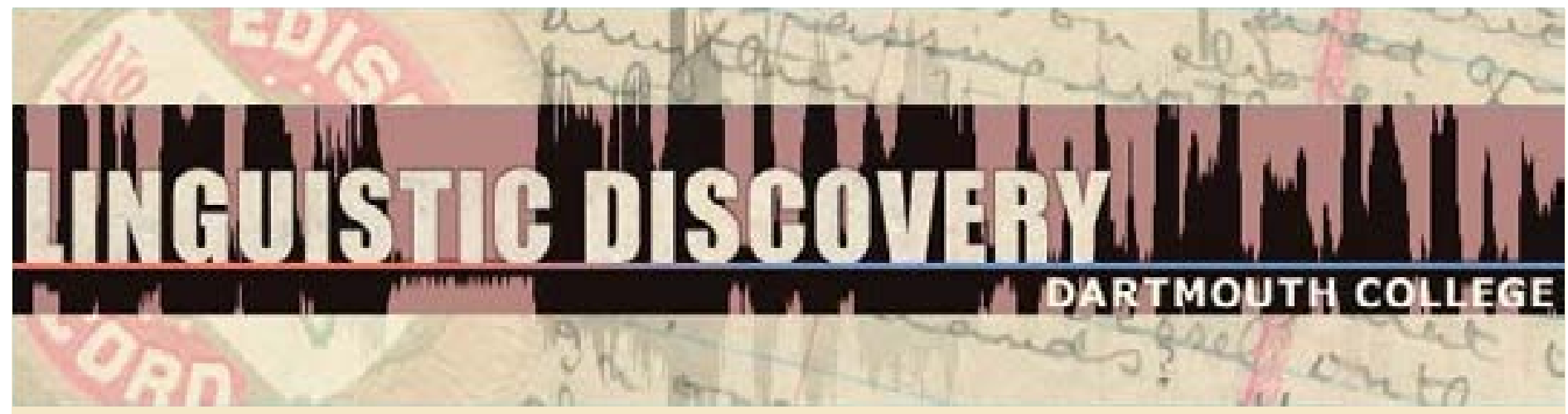

\begin{tabular}{|l|}
\hline Volume 4 \\
Issue 1 \\
2006 \\
\hline
\end{tabular}

Saying Goodbye in the Field

Lise M. Dobrin

Department of Anthropology, University of Virginia

doi: $10.1349 /$ PS1.1537-0852.A.310

url: http://journals.dartmouth.edu/cgi-bin/WebObjects/ Journals.woa/1/xmlpage/1/article/310

Linguistic Discovery

Published by the Dartmouth College Library Copyright to this article is held by the authors. ISSN 1537-0852 linguistic-discovery.dartmouth.edu 


\section{Saying goodbye in the field}

Lise M. Dobrin • Department of Anthropology • University of Virginia • dobrin@virginia.edu Linguistic Society of America • Albuquerque, NM • 7 January 2006

\section{Introduction}

"Getting started" in the field is a frequently addressed topic in "nguistic cieldwork manuals, field methods courses, and linguists"
reflections on their field experiences. Issues like finding infomants and establishing the terms of work are widely acknowledged have only recently begun to take seriously the long-term trajectories of the relationships they enter into in carrying out their re-
search, and "saying goodbye" in the field has received virtually no tention at all.

When fieldwork involves western linguists working in small enmean a withdrawal of resources and recognition by a powerful out nide other. The moment of leave-taking may thus represent a sigpower, and modernity, and its tone may have an enduring impac

\section{2. "Giving back" to} the community is good, but we must also know how to receive

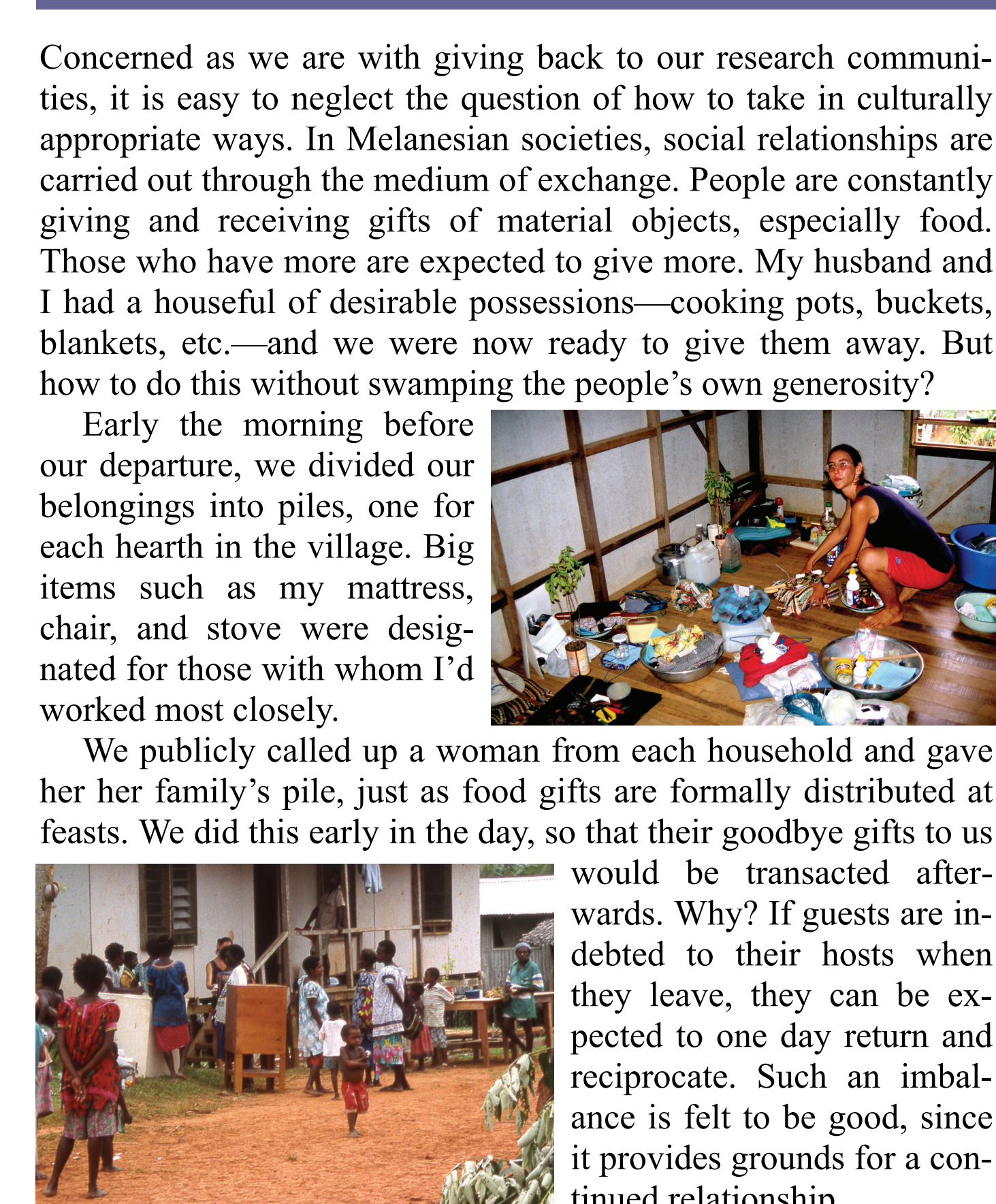

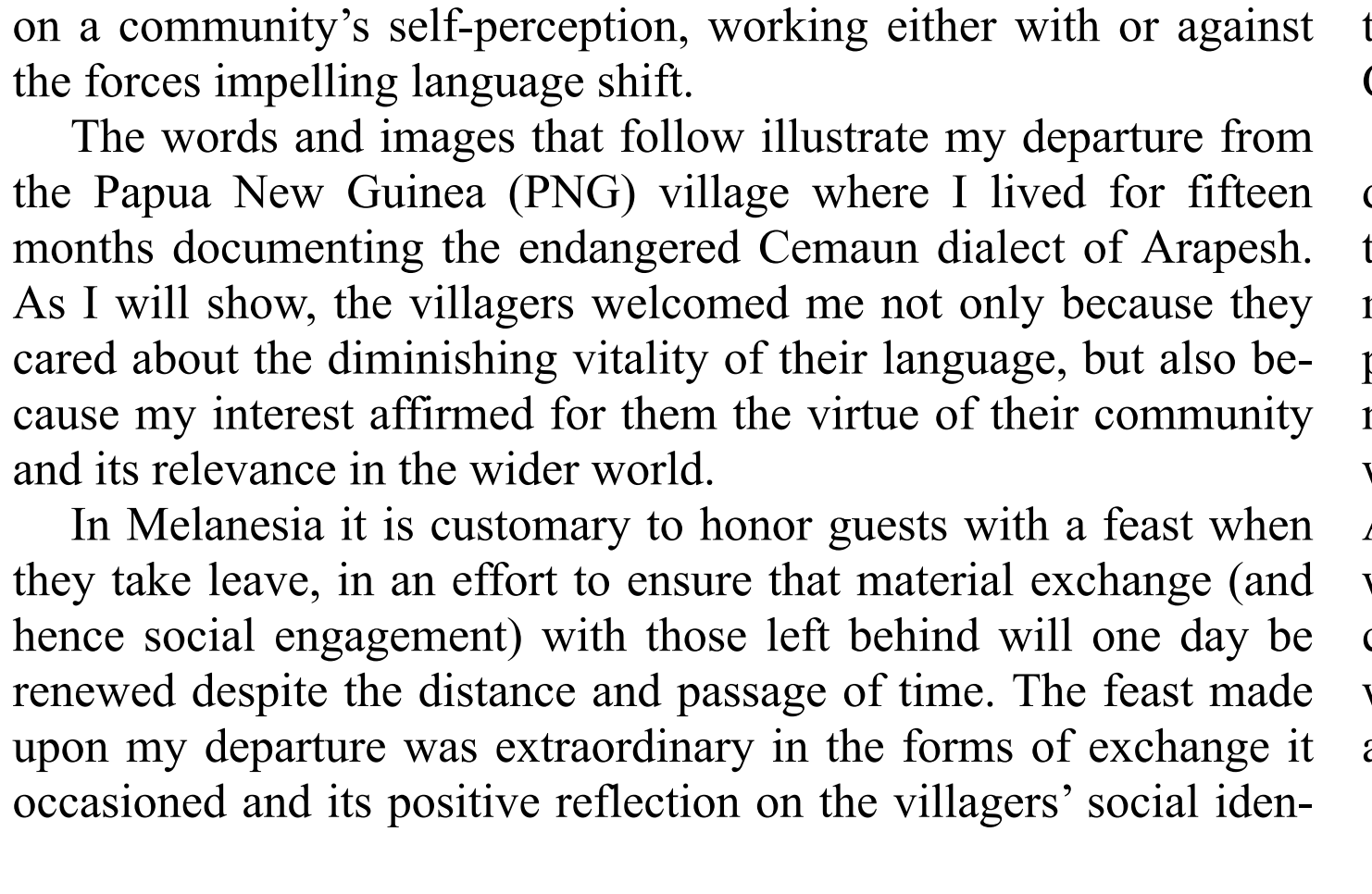

3. Good exchange relations make good public relations Members of the village diaspora, successful professionals and
prominent politicians living in the national capital, returned home
for the goodbye feast. I was

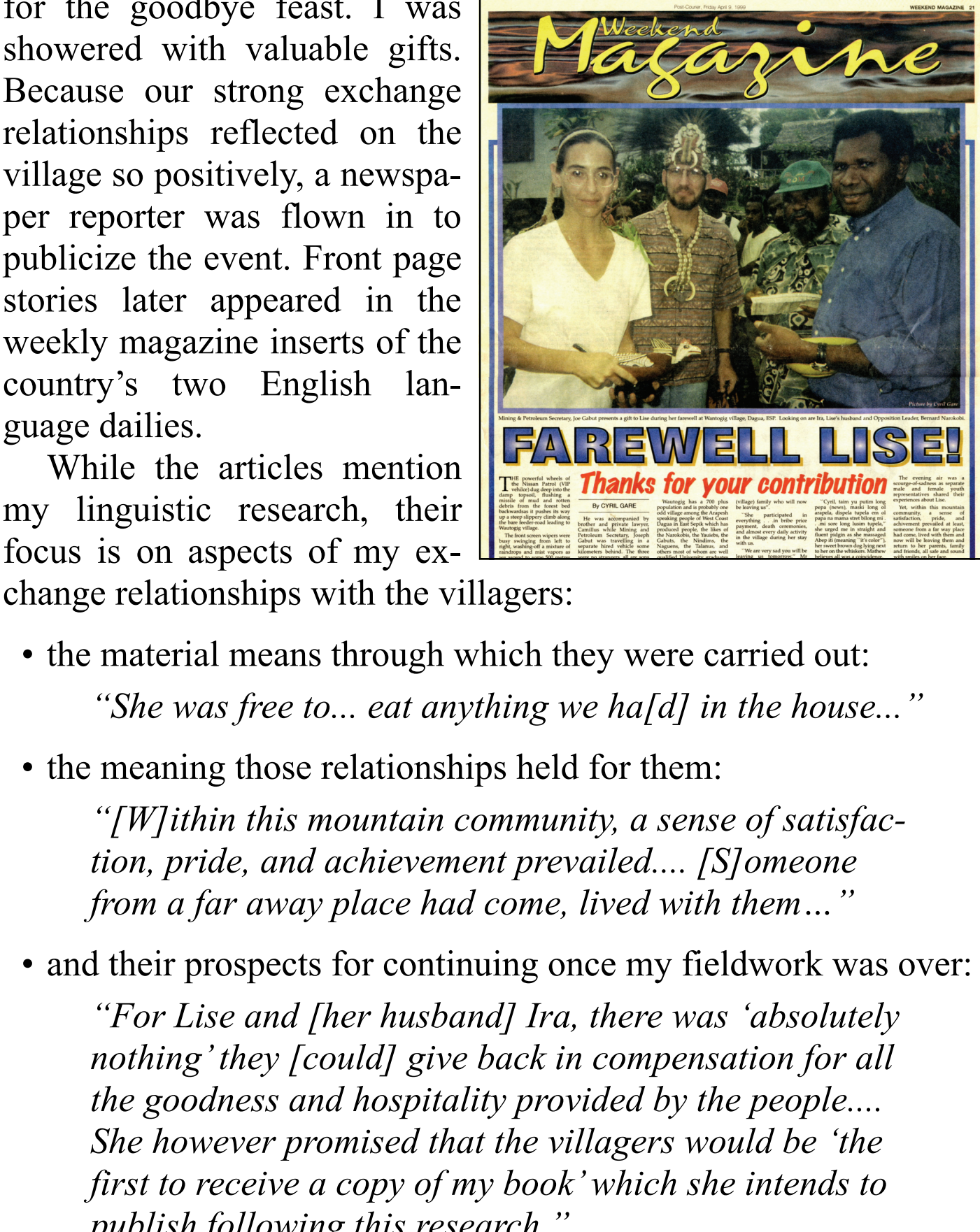

tyy. It also presented an opportunity for new and creative uses of From a western perspective, the event marked a step in the
. tion of an important project. But for the villagers, the event also
tion powerful outsider was directed specificially toward their commu-
nity, indexing its value. Once my work was finished, the villager wonderexing its value. Once my work was finished, the villages
wondere, would there still be some basis for our relationship? And I wondered whether there was any way to wind up my field-
ork and leave in this cultural context without reinforcing the community's sense of marginality, precisely what the villager
were seeking to symbolically overcome by shiffing their linguisti vere seeking to symbolically overcome by shifting the
ulegiance away from the vernacular, and onto Tok Pisi.

4. Our focus may be on the language, but theirs is on their community

People gathered in the village meeting house for farewell
speeches. In the keynote speech hiven by Bernard Narokobi,
founding father of the nation, former speaker of parliament a lounding tather of the nation, former speaker of parliament, and
respected village leader, the central theme was my work's seflec"If we in the village have helped you with your research so tha
you've learned a lot, then we will be happv Iapplausel. If we didin' do a good job help ing you and you fail, then we will be
sorry. We will be terribly sory, because we will hnow what we

"We are happy that you chose to settle here, in our village, and
not in another village that you looked at. We didn ti insist that you had to come here. I
said 'Let her look aroud

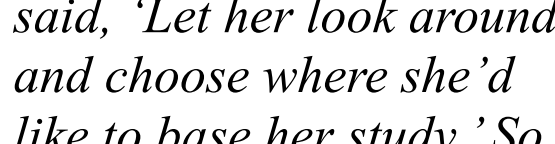
we have great respect and
onor that we were the honor that we were the was with us you decide to come stay.

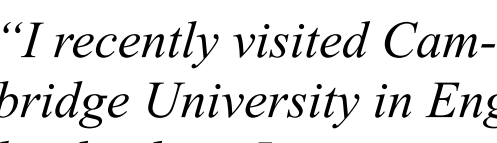
here I went to see

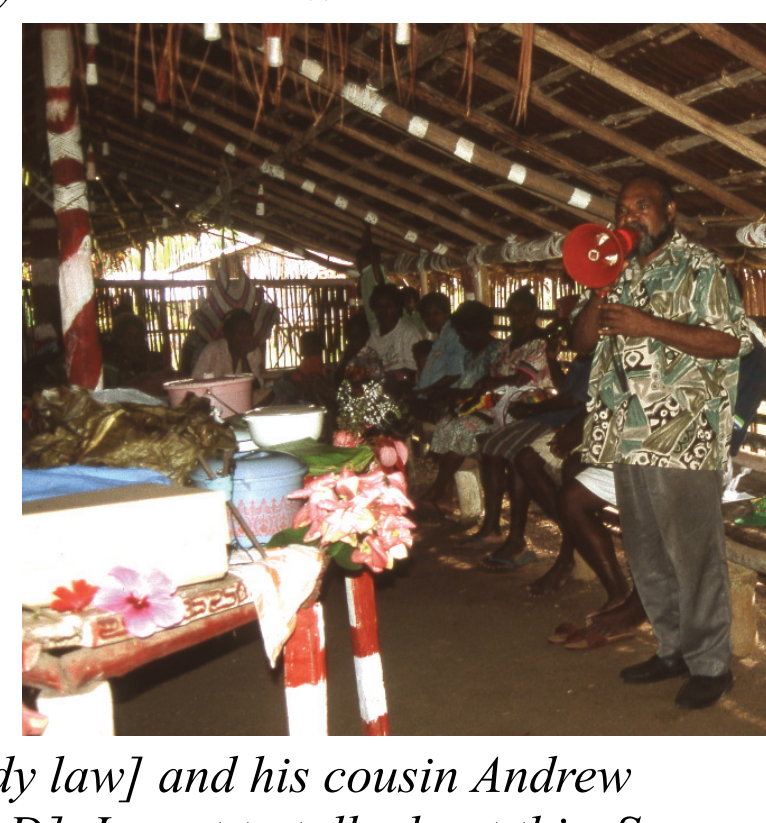
my son Vergil [there to studly law] and his cousini Andrew
Idoing an anthropology PhDl. I want to talk about this. Som

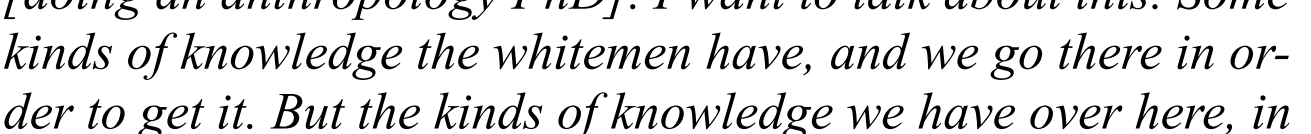
der to get it. But the kinds of knowledge we have over
order to get it the whitemen come to us applausel.
5. Harnessing the power of traditional motivations to help reinvent the vernacular

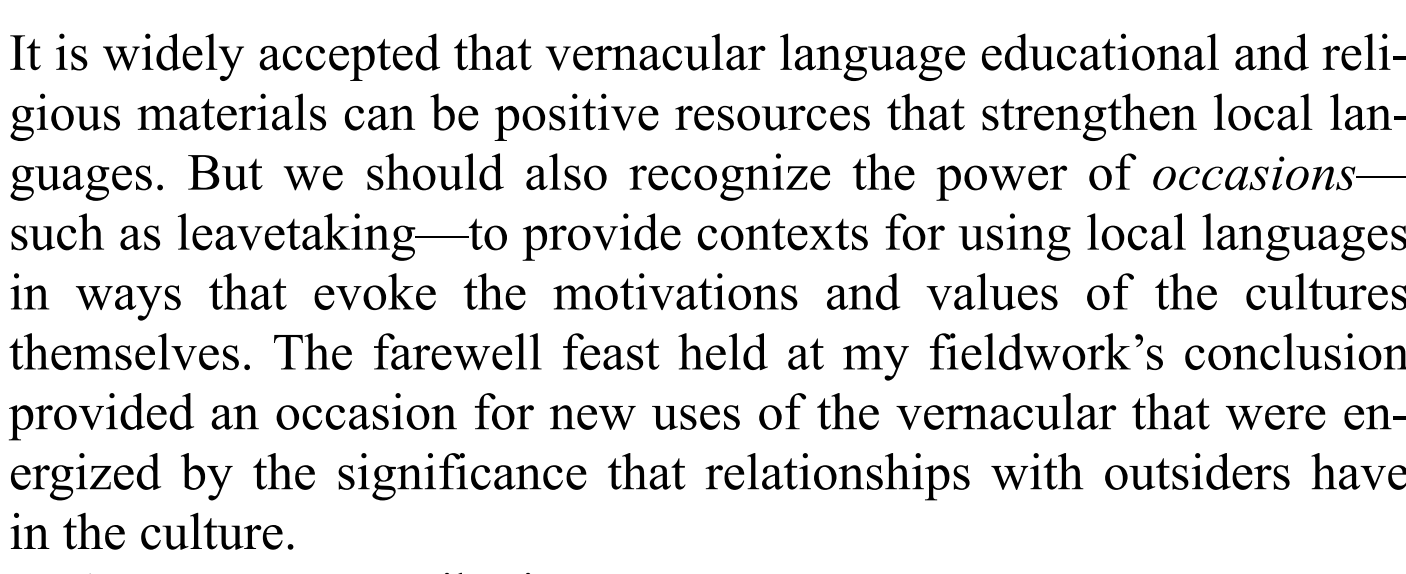

Among my contributions
to the feast was this cake. It
was decorated with writing
in Cemaun, and signed with

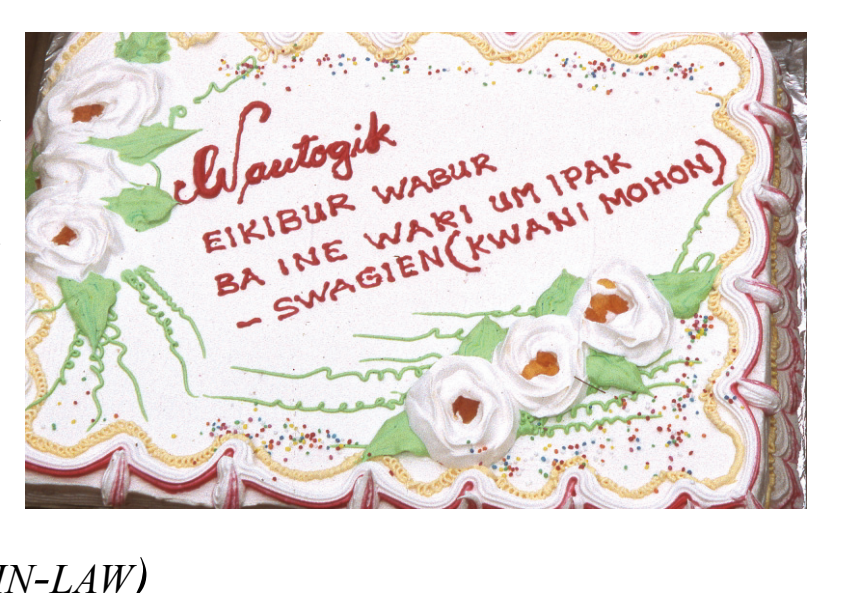

WAUTOGIK

WAUTOGIK
MY VILLAGE

- SWAGIEN (AND

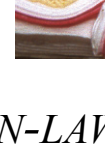

Cemaun is used but rarely now. Older villagers address it only
o one another; children often do not understand the most common

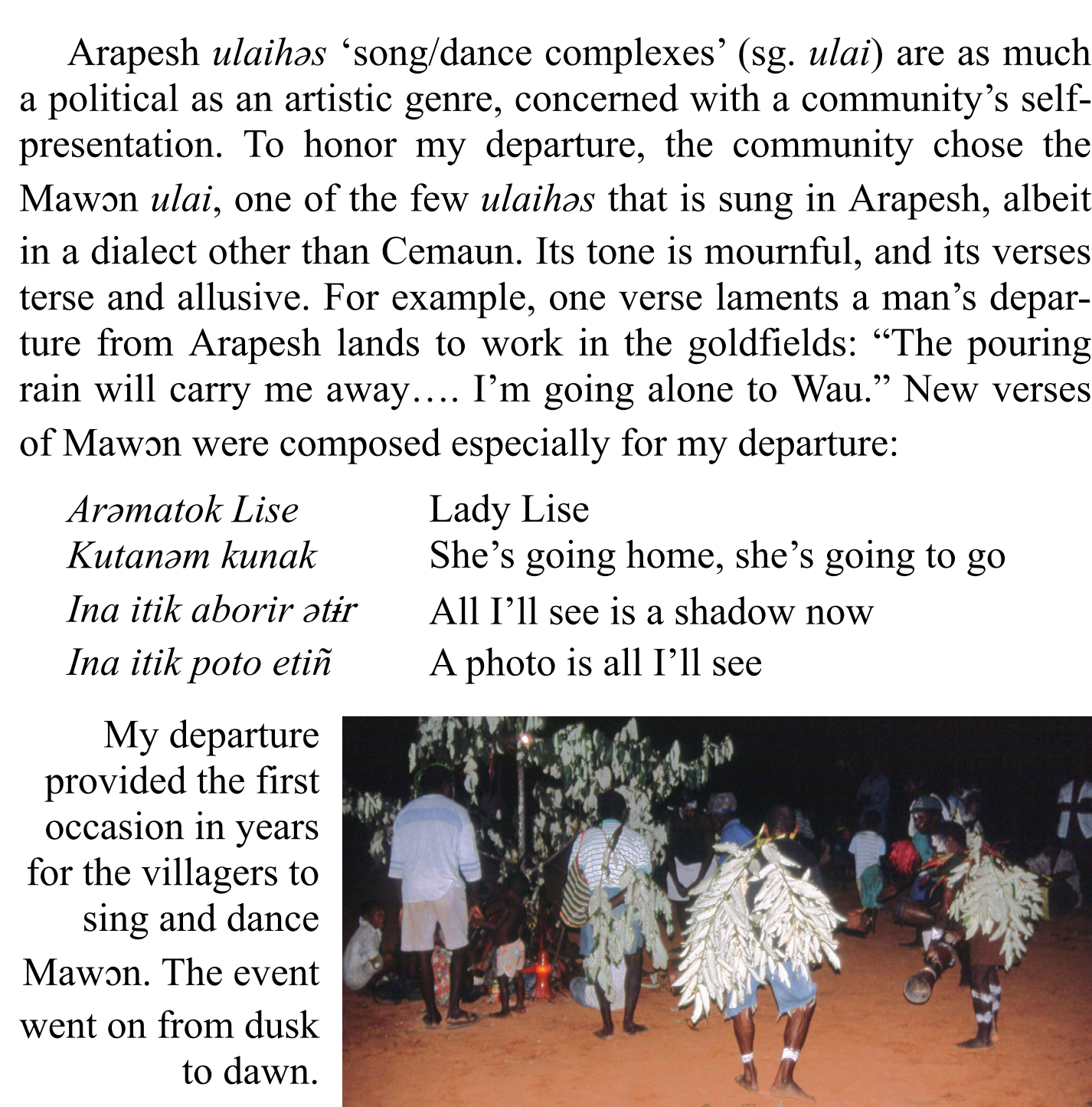

6. What this means for linguistic ffeldwork In thinking about what we can give back to our
field communities we naturally tend to focus on
he standard products of our work: dictionaries, grammars, pedagogical materials, etc. But we
must keep in mind that the relationships we form
are themselves important products of our work. ere themselves important products of our work. 1 and Departing from the field brings the relatione some of the most important issues facing the community I worked with as it negotiated it
clentity in a ched word At this sensitive identity in a changing world. At this sensitive
time I tried my best to respond to the commm focus, always in a culturally specific way that 11 nity's concern to construct a positive relationship evokes people's oun ideas about their identity in relation to cul- with me as a cultural other, recognizing that this same
tural others. Arapesh is an "importing" culture, one which values cerns was implicated in the language's endangerment.

What's at stake for the community you work with when you say goodbye in the field? 